superior to the others for a specified musical purpose is an open question and must await a proper series of trials, with adjudication by a representative body of musicians; meanwhile, those who have to pay for organs are deciding for themselves.

Accepting the musical adequacy of electronic organs, their use in churches has several artistic and technical advantages. The disposition of the sound radiators permits a fine unanimity of attack in congregational singing. Acoustical treatment to enable preachers to be heard need not spoil reverberation, which can be increased artificially to any degree desired. Finally, the great enemy of pipe-organs, cold weekdays and a warm Sunday, is rendered innocuous : electronic organs scarcely need tuning.

The craft of the organ tuner, with his mallet and cones, has started to pass; he is being replaced by an electrician, with no more equipment than is required for servicing a radio-set. There is one thing we can be certain of, no electronic organ ought to succeed unless it is finally voiced by a craftsman of tradition. If this is not insisted on, classical organ tone will not be known to the rising generation, brought up on secondhand and harsher musie, and may be lost for ever.

\title{
APPLICATIONS OF PSYCHOLOGY IN WAR CONDITIONS
}

\begin{abstract}
A SYMPOSIUM on some applications of psychology in war conditions was arranged by the Industrial Section of the British Psychological Society and held on January 25. The introductory paper was by Dr. May Smith, who gave an outline of the final report of the Health of Munition Workers Committee, published in 1918, and addressed to the Right Hon. Winston S. Churchill, M.P., then Minister of Munitions. The Committee included Sir George Newman, Sir Walter Fletcher, Sir Leonard Hill, representatives of the Home Office, members of Parliament, physiologists and pathologists. It had been appointed in September 1915 "to consider and advise on questions of industrial fatigue, hours of labour, and other matters affecting the personal health and efficiency of workers in munition factories and workshops".

At the beginning, the Committee was confronted with the width and complexity of its inquiry. The central and foremost problem was concerned with fatigue. Having realized that continuous human activity is associated with a gradually diminishing capacity, the Committee decided that the only direct test was that of output.

Views on the more theoretical aspects of fatigue were really immaterial, since it was known that the ordinary restrictions on hours of labour had been very widely relaxed, that Sunday labour previously forbidden for women and young persons and practically unknown for men, except for a few continuous processes, had become common. The employment of men for 70-90 hours a week was common, more than 90 hours was not infrequent, and there were even cases in excess of 100 hours. In short, there was a return to stme of the worst conditions of the early nineteenth century.
\end{abstract}

The Committee used two methods of getting information: (1) it took evidence from people in direct contact with workers, (2) it initiated ad hoc investigations. The first method enabled it to get information at once, the other necessitated time.

On reading through the evidence, it is impossible not to be struck by the volume and pertinence of the findings. On the whole, the evidence showed that long hours imposed too severe a strain on the workers, with the result that the rate of production tended to decrease, sickness absence and broken time to increase. Evidence of the almost intolerable strain on the management was given. The full blast of the hours was not felt at first, because the increased pay resulted in better food.

Such evidence, while overwhelming in some cases, was, however, not quantitative, and witnesses differed widely as to what constituted reasonable limits; the Committee had to emphasize the almost complete absence of any scientific data.

The appointment of Dr. H. M. Vernon and others was intended to supply this deficiency. He showed by output figures that the 12-hour day was a costly and useless procedure, that the long hours simply defeated their own end. "The country cannot afford the extravagance of paying for work done during incapacity from fatigue just because so many hours have been spent upon it," reported the Committee.

Apart from hours, environmental conditions were realized as important, and ventilation emerged out of the hands of the engineers and passed to those of the physiologist, and under the ægis of Sir Leonard Hill there entered the katathermometer. 
Lost time through sickness absence, lateness, broken periods, or just absence, soon became a formidable problem. The causes of lost time were classified into two main groups : (a) Causes mainly inherent ; for example, the employment of people of inferior physique, inadequate housing and transport facilities, wintry weather, darkened streets and inequalities of food supply, the domestic duties of married women, the warpreoccupation and exigencies of all workers, sickness and disease caused by conditions outside the factory. (b) Causes mainly controllable; for example, fatigue, sickness and accidents of factory origin, insufficient wage incentive, faulty internal organization, indifference, slackness, laziness, discontent, prolonged hours, overtime, insufficient rest periods or holidays, and excessive consumption of alcoholic beverages.

The Committee came to the conclusion that the absence through sickness was considerably underestimated, and pointed out that if there is an undue proportion of sickness in any group of workers there is also likely to be lessened vigour and activity among those who are not away sick. It noted the absence of adequate records, partly due to difficulty in regard to medical certificates and partly because minor illnesses were not reported.

The section on incentives starts off, not with wages or bonuses, but with the statement that "the first incentive is the health and physical fitness of the worker", and although the Committee confined itself to the factory conditions contributing to that, yet the field covered is very wide. Only after this does the Committee discuss wages, which must be "well adjusted, equitable and clearly understood".

The Committee notes that "what is needed is not a cast-iron system of employment but a sympathetic or correct understanding of the physical and mental capacities of each worker and their most satisfactory and economical application".

The present War has introduced many of the conditions of the War of 1914-18, but already after four months there are signs of an interest not aroused until after thirteen months before; happily we are better equipped now than in 1914 .

Dr. Vernon took up the discussion, pointing out that excessive hours constitute a major problem when increased output is urgent. Many employers cannot grasp the fact that, after a certain number of hours of work, the worker is so fatigued that production falls. Some investigations undertaken during the War of 1914-18 showed that the actual gross output-not merely the average hourly output-is less on a 12-hour day than on a 10 hour. It is true that in the early stages of a war, patriotism plays a definite part in keeping up the output, and in the last War employers often defended the excessive hours on these grounds; but Nature cannot be defied indefinitely and many men and women were in a chronic state of fatigue. For many processes in munition work, Dr. Vernon found that output is a very satisfactory measure of the effects of hours of work, since the same materials are being used and the same articles made, the only important variable being the number of hours worked. Sunday labour, except for emergencies, proved wholly unsatisfactory, in spite of the extra pay: it has been described as "8 days' pay for 7 days' work with 6 days' output".

The problems involved in night-shift work are not easy to solve, for, quite apart from the organization within the factory, there are complications connected with the domestic arrangements of the workers and transport.

With regard to the material environment, Dr. Bedford pointed out that there is now available considerably more scientific knowledge than in 1914. Numbers of researches have been made to find out the relationship of lighting, heating and ventilation conditions to efficiency, comfort, accidents, and health. The last twenty-five years have shown a pronounced tendency to have more light, not only for fine work but also in general : a good light is felt to be more cheerful. Working all day in artificial light gives people a feeling of being cheated; if, however, owing to the nature of the work, this is inevitable, much can be done by the use of extended light services and by arranging artificial windows and similar devices.

Heating and ventilation cannot be kept separate. It used to be considered adequate if the air was pure and stimulating: now increased emphasis is laid on the need for an adequate degree of warmth as well. As with lighting, the standard of warmth has gone up; many factories used to be below $50^{\circ} \mathrm{F}$., whereas recently a research worker experienced difficulty in finding one below $55^{\circ}$. For the full assessment of thermal conditions a single yardstick, however, is impossible; individual conditions have to be considered and weighed.

The recent 'black-out' regulations have added to the difficulties of factories relying on open windows, so that there are many complaints of stuffiness and overheating. Forms of light-traps, however can be devised, which allow of the entrance and exit of air while complying with the lighting regulations.

Dr. Millais Culpin said that since 1914 considerable progress has been made both in the diagnosis and treatment of psycho-neurotic illness. The last War took us unawares, with few doctors capable of treating such illness or even of recognizing its existence. Psychological casualties in the civilian population under direct war risk may be 
fewer than we might expect, for the civilian is allowed to show manifest fear or to run away. That some kinds of psychoneurotic people should retire to the West Country - as many did during 1914-18 - is best for everybody. He regretted the use of a phrase now rather popular, namely, 'fright neurosis'. Fear is of biological significance, and to be afraid, even greatly afraid, is, in some conditions, a natural reaction. Pathological fear is in a very different category, the reaction being usually quite inadequate to the situation.

Nor is it right to class all psychoneurotics in one group; some of them can be diagnosed as likely to break down in peace or war, and some will not; others will withstand the most difficult conditions. Some who had managed to adjust themselves to the last War and to the years since have broken down now, suppressed memories of the last War being touched up. To confuse such cases with 'fright neurosis' is disastrous.

How civilians will behave in air raids is difficult to predict. It is possible that some with a high degree of claustrophobia will prefer to be bombed rather than have the feeling of being in an enclosed space; within a shelter some may faint, and others may adjust to the circumstances although feeling considerable discomfort. With regard to the question of what can be done with cases of uncontrolled behaviour or of those who faint in an air-raid shelter, Dr. Culpin said that the fainting neurotic might be left to himself, while harsh treatment might be needed for others.
Two schools exist in the medical profession with regard to the treatment of the neurotic who has broken down: one is the school which would diagnose and treat by psychological means, and the other he called the 'kick in the pants' school. Fortunately for the world, the latter is found chiefly among the elderly, who are despised by the younger and more adequately trained doctors.

Mr. Alec Rodger, discussing the selection and grading of personnel, said that a great stimulus to this was provided by the Americans in the War of 1914-18. In order to sort out people fit for different kinds of training, nearly two million men were given intelligence tests. The experiment proved so successful that other countries, including Germany and the U.S.S.R., have adopted similar intelligence testing procedures. Mechanical aptitude tests have also been widely employed. Both intelligence and mechanical aptitude tests and other psychological techniques are used to a limited extent in our own fighting Services.

The value of tests in the grading of personnel needs special emphasis. Many are accustomed to think of them only as instruments in the selection of men and overlook the fact that they can be used effectively in the grading process, the aim of which is to arrange that individuals of similar abilities are instructed together. Mr. Rodger added that, since intelligence tests had been used by many school and other authorities over a period of years, much data of value to the Services could probably be made available immediately.

\section{CENTRAL REGISTER OF SPECIALISTS}

\section{(Section for Scientific Research)}

IN the issue of NATURE of April 8, 1939, p. 575, there was an account of the establishment by the Royal Society and the Ministry of Labour jointly of the Central Register of Specialists (Section for Scientific Research), with the main aim of providing a list of scientific workers whose professional services might be useful in time of war. It will be remembered that each scientific worker was asked to fill in a card giving an account of his qualifications and some details of his career. From the point of view of the Royal Society the register also had a secondary purpose, for, if there were not to be a war, then it was felt that this was a good opportunity to obtain a census of the scientific knowledge of the country which would be of general value. With the outbreak of war the main purpose of the register was called into play, even before its compilation was complete, and it will be of interest to give a short account of some of its consequent workings. This article only deals with the register of men of science, and does not touch on the similar work of the Ministry of Labour in other branches of learning or technology.

In the spring of 1939, cards were sent out to men and women whose names had been furnished by certain learned societies. Up to the end of July a little short of eight thousand had been sent out and some five thousand replies received. Since July, several hundred more have been sent out to people who had been missed in the earlier lists, and the total number of cards returned is now more than six thousand. This list is largely composed of names from universities, from industries and from the research associations. Men already in the Government service have also been permitted to send in their cards, so that they are 